\title{
Effects of a reduced efficacy of the KCC2 co- transporter in temporal lobe epilepsy: single neuron and network study
}

\author{
Anatoly Buchin ${ }^{1,2^{*}}$, Gilles Huberfeld ${ }^{3,4}$, Richard Miles ${ }^{5}$, Anton Chizhov ${ }^{6}$, Boris Gutkin ${ }^{1,7}$ \\ From 24th Annual Computational Neuroscience Meeting: CNS*2015 \\ Prague, Czech Republic. 18-23 July 2015
}

Epilepsy is one of the most common neurological disorders. Seizures in about $40 \%$ of patients with temporal lobe epilepsies are pharmaco-resistant [1]. In surgically removed hippocampal tissue from these patients, the $\mathrm{KCC} 2$ cotransporter is absent or non-functional in about $20 \%$ of subicular pyramidal cells [2]. KCC2 normally assures the maintenance of low intra-neuronal chloride levels [3] and also regulates potassium levels [4]. Chloride concentration changes in the remaining pyramidal cells due to intensive GABAergic input during seizures could reverse the effects of GABA currents from inhibitory to excitatory $[5,6]$. Such changes may shift a pyramidal cell into a periodic bursting regime associated with ictal discharges. Using a detailed biophysical model of a single cell incorporating these mechanisms of ionic homeostasis and a neural network model, we show that decreasing the activity of $\mathrm{KCC} 2$ pump leads to repetitive seizure-like firing in the pathologic network due to increased extracellular potassium and intracellular chloride (Fig. 1). This model provides insights into how a dysregulation of pyramidal cell chloride homeostasis due to reduced levels of the KCC2 cotransporter may lead to seizures in the epileptic human subiculum.

\section{Acknowledgements}

This work has been supported by the following grants: ANR-10-LABX-0087 IEC, ANR-10-IDEX-0001-02 PSL, ERC-322721, FRM FDT20140930942. Especially we would like to thank Giri Krishnan for useful discussions.

\section{Authors' details}

'École normale supérieure, Laboratoire des Neurosciences Cognitives, Group for Neural Theory, Paris, France. ${ }^{2}$ Peter the Great St.-Petersburg Polytechnic University, St.-Petersburg, Russia. ${ }^{3}$ Neurophysiology Department, Pitie-

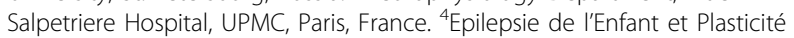
Cérébrale, INSERM U1129, Paris, France. ${ }^{5}$ Institut du Cerveau et de la Moelle Epiniere, Cortex et Epilepsie Group, Paris, France. ${ }^{6}$ Ioffe Physical Technical Institute, Computational Physics Laboratory, St.-Petersburg, Russia. ${ }^{7}$ Higher

School of Economics, Moscow, Russia.

Published: 18 December 2015

\section{References}

1. Beghi E, Berg A, Carpio A, Forsgren L, Hesdorffer DC, Hauser WA, Tomson T: Comment on epileptic seizures and epilepsy: definitions proposed by the International League Against Epilepsy (ILAE) and the International Bureau for Epilepsy (IBE). Epilepsia 2005, 46(10):1698-1699.

2. Huberfeld G, Wittner L, Clemenceau S, Baulac M, Kaila K, Miles R, Rivera C: Perturbed chloride homeostasis and GABAergic signaling in human temporal lobe epilepsy. J Neuroscience 2007, 27(37):9866-9873.

3. Blaesse P, Airaksinen MS, Rivera C, Kaila K: Cation-chloride cotransporters and neuronal function. Neuron 2009, 61(6):820-838.

4. Payne JA: Functional characterization of the neuronal-specific $\mathrm{K}-\mathrm{Cl}$ cotransporter: implications for $[\mathrm{K}+]$ oregulation. American Journal of Physiology-Cell Physiology 1997, 273(5):C1516-C1525.

5. Khalilov I, Dzhala V, Ben-Ari Y, Khazipov R: Dual role of GABA in the neonatal rat hippocampus. Developmental Neuroscience 1999, 21(35):310-319.

6. Jedlicka P, Deller T, Gutkin BS, Backus KH: Activity-dependent intracellular chloride accumulation and diffusion controls GABA-A receptor-mediated synaptic transmission. Hippocampus 2011, 21(8):885-898.

doi:10.1186/1471-2202-16-S1-P5

Cite this article as: Buchin et al.: Effects of a reduced efficacy of the KCC2 co-transporter in temporal lobe epilepsy: single neuron and network study. BMC Neuroscience 2015 16(Suppl 1):P5.

\footnotetext{
* Correspondence: anat.buchin@gmail.com

'École normale supérieure, Laboratoire des Neurosciences Cognitives, Group for Neural Theory, Paris, France

Full list of author information is available at the end of the article
} 


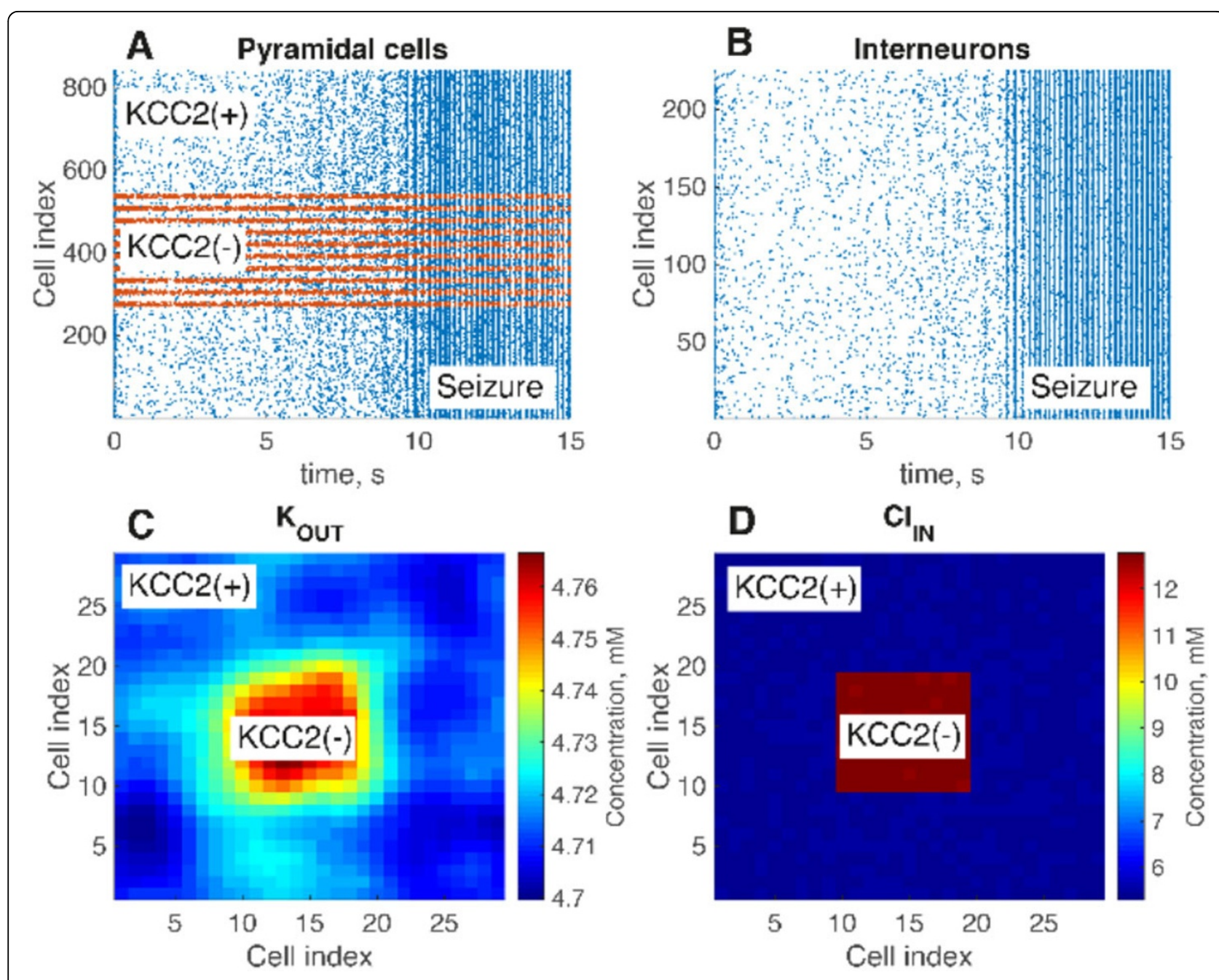

Figure $1 \mathrm{~A}$ raster plot of pyramidal cell population firing; B raster plot of interneuron firing; C spatial distribution of extracellular potassium; D intracellular chloride distribution. 